\title{
Improving the classroom listening skills of children with Down syndrome by using sound- field amplification
}

\author{
Lee K. Bennetts and Mark C. Flynn \\ Department of Speech and Language Therapy, University of Canterbury, New Zealand
}

\begin{abstract}
Many children with Down syndrome have fluctuating conductive hearing losses further reducing their speech, language and academic development. It is within the school environment where access to auditory information is crucial that many children with Down syndrome are especially disadvantaged. Conductive hearing impairment which is often fluctuating and undetected reduces the child's ability to extract the important information from the auditory signal. Unfortunately, the design and acoustics of the classroom leads to problems in extracting the speech signal through reduced speech intensity due to the increased distance of the student from the teacher in addition to masking from excessive background noise. One potential solution is the use of sound-field amplification which provides a uniform amplification to the teacher's voice through the use of a microphone and loudspeakers. This investigation examined the efficacy of sound-field amplification for 4 children with Down syndrome. Measures of speech perception were taken with and without the sound-field system and found that the children perceived significantly more speech in all conditions where the sound-field system was used $(p<.000 \mathrm{I})$. Importantly, listening performance with the sound-field system was not affected by reducing the signal-to-noise ratio through increasing the level of background noise. In summary, sound-field amplification provides improved access to the speech signal for children with Down syndrome and as a consequence leads to improved classroom success.
\end{abstract}

Keywords - sound-field, FM, assistive listening devices, audiology, hearing loss, signal-to-noise ration, amplification, classroom listening, classroom acoustics

\section{Introduction}

The hearing problems associated with Down syndrome are well documented in the literature with reported incidence of hearing loss ranging from $65 \%$ to $70 \%$ (Maurizi, Ottaviani, Paludetti \& Lungarotti, 1985; Miller, Leddy \& Leavitt, 1999; Roizon, Wolters, Nicol \& Blondis, 1993). The most frequent type of hearing loss is a mild conductive bilateral loss (Roizon et al. 1993; Miller et al., 1999; Maurizi et al., 1985). Miller et al. (1999) studied children with Down syndrome over a three year period and that found $33 \%$ of the children always had a hearing loss, $33 \%$ never had a hearing loss and $33 \%$ had a fluctuating hearing loss.

Any hearing loss has significant implications (Roberts, Wallace \& Henderson, 1997). A mild conductive loss, similar to that frequently seen in children with Down syndrome affects both speech and language development and consequently other areas of development. Miller et al. (1999) reported children with recurring hearing losses are at risk of speech-language delays. Children with Down syndrome have specific deficits in language (Chapman, Schwartz, \& Bird, 1991), which is exacerbated by frequent middle-ear infections with resulting conductive hearing loss.

With increased inclusion of children with Down syndrome in mainstream classrooms, increased emphasis is placed on the child's ability to listen and learn within the typical classroom. The typical classroom is an auditory-verbal environment where learning takes place through listening and speaking (Flexer, 1997a; Palmer, 1997). In fact 50-90\% of information being taught is obtained through the auditory channel (Schmidt, Andrews \& McCutcheon, 1998) and children spend at least $45 \%$ of the school day engaged in listening activities (Berg, 1987). The underlying assumption is that children can hear the teacher's speech clearly and that they can pay attention (Flexer, 1997a). Unfortunately, this may not always be the case, especially for children with Down syndrome who often have a concurrent hearing loss. According to Flexer (1997a) if a child cannot hear the teacher clearly and consistently then a major premise of the educational system is undermined. There are two 
reasons for this. First, hearing loss has been described as an "invisible acoustic filter that distorts, smears or eliminates incoming sounds, especially sounds from a distance" (Flexer, 1997b, p. 7). The implication is that a teacher does not know how well a child is hearing at any one time. Second, a classroom is one environment where the child is frequently expected to hear sounds from a distance. Classroom acoustics further impact on children's difficulties.

Unfortunately, the modern classroom has been described as providing a hostile environment for listening (Flexer, 1997a; McSporran, 1997). Inadequate in terms of signalto-noise ratio, reverberation, background noise levels, and distance from the teacher (Arnhold \& Canning, 1999; Allcock, 1999; Blake \& Busby, 1999; Flexer, 1997a; Flexer, 1997b; Flynn, 2000; Palmer, 1997). These conditions are disadvantageous to all children and especially those with hearing impairments. Therefore, for children with Down syndrome who are prone to middle ear infections, often resulting in undetected fluctuating conductive hearing impairment, the effects of poor classroom acoustics become crucial. A solution needs to be found that will enable the child with Down syndrome to regain access to the complete auditory signal and therefore maximise classroom success.

Frequency modulated (FM) sound-field amplification may provide a practical and cost-effective solution. The soundfield amplification system is a small high-fidelity wireless public address system that is self-contained in a classroom (Flexer, 1997b). The aim is to amplify the teacher's voice so that it is delivered clearly and consistently to all pupils (Flexer, 1997b) resulting in a consistent and favourable signal-to-noise ratio. Recently, a number of research articles examined the efficacy of sound-field amplification. Allcock (1999) considered the effects of sound-field amplification through measuring time on task behaviour and measures of speech intelligibility in junior classrooms. The research showed that on average children spend $18 \%$ more time on-task when the sound field was on. Those with hearing impairments also spent significantly more time on-task. Additionally, sound field amplification improved the children's ability to discriminate speech sounds in words. Massie, Theodoros, Byrne, McPherson and Smaldino (1999) observed children in classrooms with and without sound-field and found increases in the spontaneous contributions made by children in class, improvements in perception of speech and an increase in the children's interaction with each other when sound field was used. Similarly, Arnhold and Canning (1999) examined comprehension of children with the sound-field on and off and found that when the sound-field was on the children's comprehension of speech improved. All of these improvements can be attributable to the improved signal-to-noise ratio that the soundfield system provides to every student in the classroom. According to Sapienza, Crandell and Curtis (1999) teachers benefit in other ways. The study concluded that teachers using sound-field amplification significantly reduced the sound pressure levels of their voice during classroom instruction. Sound-field amplification can therefore be used as part of a vocal hygiene regimen to counteract the vocal fatigue, hoarseness and voice disorders often experienced by teachers.

All children in the classroom, irrespective of whether they have a hearing loss, can benefit from sound-field amplification (Flexer, 1997a), and especially children with Down syndrome who often have fluctuating hearing loss. A listening environment in which the auditory signal is clear and consistent enhances learning. According to Flexer (1997a) sound-field amplification is particularly appropriate for those with hearing impairments, auditory processing deficits, language, learning, attention or behaviour problems. In all these areas a child with Down syndrome could benefit. In many cases the child with Down syndrome may be wearing hearing aids. Unfortunately, hearing aids may not always provide the an optimum solution within the classroom setting as the hearing aid will amplify both the teacher's voice and the background noise. Hence, the teacher's voice is made sufficiently loud but the problem of a poor signal-to-noise ratio remains as the background noise is also amplified (Flexer, 1997b). Conversely, soundfield amplification by amplifying only the teacher's voice increases the signal-to-noise ratio to the child, so that the hearing aid amplifies this good signal rather than one masked by background noise. Hence, depending on the degree of hearing loss, the optimal solution may be to wear hearing aids to improve the audibility of the speech signal in combination with a sound-field system to improve the signal-to-noise ratio within the classroom (Westerveld \& Flynn, 2001). Sound-field amplification is particularly appropriate for students with fluctuating conductive losses, which is widespread amongst children with Down syndrome. This technology allows the child's hearing to fluctuate without being at risk of missing valuable learning experiences within the classroom because they cannot hear.

Unfortunately, the efficacy of sound-field amplification for children with Down syndrome has not yet been considered. Sound-field amplification is a potentially viable solution to counteract the listening difficulties these children with Down syndrome face in the classroom. Therefore, the aim of the present study is to consider the efficacy of soundfield amplification for children with Down syndrome.

\section{Method}

\section{Participants}

Four children ( $5 ; 11$ to $7 ; 3$ years) with Down syndrome participated in this project (Table 1). The children were volunteers from the Down Syndrome Association of New Zealand.

All the participants had a full audiological assessment within two weeks of the investigation. Table 2 presents the Pure Tone Audiometry (PTA) averages for the participants and their tympanometry results. As can be seen from these results the children participating in the study received 


\begin{tabular}{|lll|}
\hline Participant & Age & Gender \\
\hline 1 & $5 ; 11$ & Male \\
2 & $5 ; 8$ & Female \\
3 & $7 ; 1$ & Female \\
4 & $7 ; 3$ & Female \\
\hline Table I. Participants' age and gender \\
\hline
\end{tabular}

\begin{tabular}{|l|lc|ll|}
\hline \multirow{2}{*}{ Participant } & \multicolumn{2}{|l|}{$\begin{array}{l}\text { Pure-tone Average of } \\
500,1000 \text { \& 2000Hz. }\end{array}$} & \multicolumn{2}{|l|}{ Tympanometry } \\
\cline { 2 - 5 } & $\begin{array}{c}\text { Left Ear } \\
\text { (dBHL) }\end{array}$ & $\begin{array}{c}\text { Right Ear } \\
(\mathrm{dBHL})\end{array}$ & Left Ear & Right Ear \\
2 & 16 & 21 & $\mathrm{~A}$ & $\mathrm{C}$ \\
3 & 23 & 21 & $\mathrm{VT}$ & $\mathrm{VT}$ \\
4 & 13 & 15 & $\mathrm{~B}$ & $\mathrm{~A}$ \\
& 13 & 15 & $\mathrm{VT}$ & $\mathrm{VT}$ \\
\hline Table 2. Audiological Assessment Results \\
VT - Ventilation Tube \\
A - Normal compliance \\
B - Reduced compliance/middle ear fluid \\
C - Eustachian tube dysfunction \\
\hline
\end{tabular}

\begin{tabular}{lcccccl}
\hline & OFF & OFF & OFF & ON & ON & ON \\
\hline Noise: & 50 & 55 & 60 & 50 & 55 & 60 \\
SNR & +10 & +5 & +0 & +20 & +15 & +10 \\
1 & 9 & 5 & 4 & 10 & 10 & 10 \\
2 & 9 & 8 & 4 & 10 & 10 & 10 \\
3 & 10 & 8 & 3 & 10 & 10 & 10 \\
4 & 6 & 0 & 0 & 8 & 10 & 8 \\
Average & 8.5 & 5.25 & 2.75 & 9.5 & 10 & 9.5 \\
\hline
\end{tabular}

Table 3. Speech perception scores with background noise (scores out of 10)

\begin{tabular}{lrrrrc}
\hline Source & df & SS & \multicolumn{1}{c}{ MS } & \multicolumn{1}{c}{ F } & P \\
\hline Covariates (subjects) & 3 & 41.500 & 13.833 & 7.69 & $=.002$ \\
Sound-field & $\mathrm{I}$ & 104.167 & 104.167 & 57.87 & $<.0001$ \\
SNR & 2 & 33.083 & 16.542 & 9.19 & $=.002$ \\
Sound-field *SNR & 2 & 34.083 & 17.042 & 9.47 & $=.002$ \\
Error & 15 & 27.000 & 1.800 & & \\
Total & 23 & 239.830 & & & \\
\hline
\end{tabular}

Table 4. Analysis of Variance (Balanced Designs)

excellent auditory management and had very mild if any hearing loss.

\section{Test materials and procedures}

The children participated in one session with the soundfield amplification on and one with it off. The test order and sessions were randomised for each child to control for the effects of learning the assessment procedures. The investigator wore the microphone in all sessions regardless of whether the sound-field was being used. The sound-field amplification was pre-set to give $10 \mathrm{~dB}$ of gain to the inves-

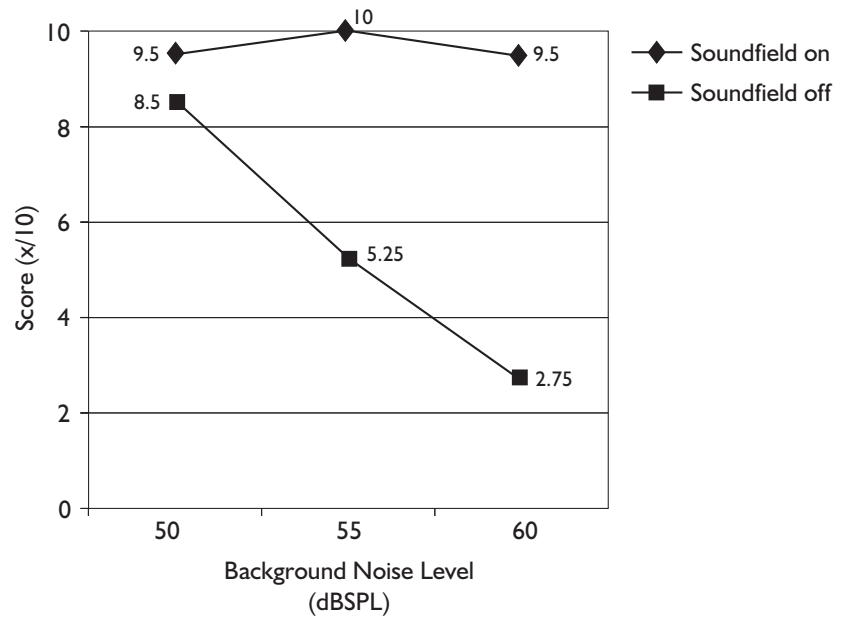

Figure I. Mean scores for each condition clearly showing that sound field FM systems remain impervious to the effects of increased noise levels.

tigator's voice. For speech perception testing, the investigator spoke at a level of $60 \mathrm{dBA}$ (peak) when one metre from the sound level meter. This resulted in a $70 \mathrm{dBA}$ signal when the sound-field amplification was being used. Before each session a background noise reading was taken every minute for five minutes and then an average background noise reading for that session calculated. The sound level meter was always placed under the video microphone when the readings were taken.

To assess speech perception the Kendall Toy Test (KT; Kendall, 1962) was used. The test consists of five different balanced lists, of which two were randomly selected. Each list has 12 common objects ( 10 test items and 2 foils), which are placed in front of the child. A training session was included to ensure that the participants knew the names of all of the toys. The child was asked to point to the object that the investigator said and the participant's response recorded. The investigator's voice was consistently at $60 \mathrm{dBA}$ (ensured using the sound level meter) and the investigator's mouth was covered to prevent the participants relying on visual cues but not so that it affected the acoustic signal. When the sound-field amplification was on the investigator's voice was amplified by $10 \mathrm{dBA}$. Background noise (cafeteria noise) was presented at $50 \mathrm{dBA}, 55 \mathrm{dBA}$, and $60 \mathrm{dBA}$.

\section{Equipment}

A Sony TCM-5000EV tape recorder was used to present the background noise in the speech perception test. The background noise used in the speech perception test was Auditec of St Lewis cafeteria noise. All sessions were videoed using standard video recording equipment. All sound level recordings were taken using a sound level meter (Bruel \& K.Jaerr, \#2225) and measurements were taken in dBA. The sound-field amplification system used was an Easy Listener sound-field system supplied by Phonic Ear. This system had four standing speakers and a wireless FM microphone. 


\section{Results}

The Kendall Toy Test (KT; Kendall, 1962) with cafeteria noise at $50 \mathrm{dBA}$, then $55 \mathrm{dBA}$ and finally at $60 \mathrm{dBA}$ was the assessment tool used to determine the participant's speech perception abilities. Table 3 presents the number of words correctly perceived (out of 10) at each background noise level with and without the FM sound field amplification.

An analysis of variance (Table 4 ) indicated that the participant's speech perception significantly improved $(p<.0001)$ when the FM sound field amplification was being used. Additionally a significant effect $(p=.002)$ and interaction effect $(p=.002)$ was found for the use of sound-field and background noise. As can be seen from Figure 1 the condition with sound-field off showed a significant decrease in speech perception with each increase in signal-to-noise level whereas having the sound-field on did not. Hence, the sound-field ensures that the child at all times receives an excellent signal-to-noise ratio. These results, while on a limited sample size, clearly indicate that sound-field amplification improves the speech perception skills of the children with Down syndrome.

\section{Discussion}

The present investigation examined the efficacy of soundfield amplification for children with Down syndrome. The findings suggest that sound-field amplification improves the speech perception of children with Down syndrome by providing an advantageous listening environment. As discussed earlier, if a child cannot hear then a major premise of the educational system is undermined (Flexer, 1997a). Therefore, to maximise the speech perception of children with Down syndrome within the classroom, sound-field amplification should be used.

A limitation of this research related to the participants themselves. Due to the limited number of children with Down syndrome within the region, only four children participated in the research. Despite this reduced number of participants, the results are very encouraging for the use of sound-field to improve the educational environment of children with Down syndrome. Additionally, the children who participated only had a mild hearing loss. Hence, the effects of sound-field amplification would be even greater with increased hearing loss. Further investigation is warranted with children with Down syndrome who have greater hearing losses, to confirm that this is indeed the case.

Previous research with sound-field amplification has focused on typically developing children. Children with Down syndrome frequently have a fluctuating conductive hearing loss (Davies, 1985; Maurizi et al., 1985; Miller et al., 1999; Roizon et al., 1993). This loss effects speech perception and consequently learning is effected. While hearing aids and other assistive listening devices provide a solution for permanent hearing impairment they are often inappropriate where the hearing loss is fluctuating. In particular, it is difficult for the teacher and family to determine the peaks and troughs in hearing and set the hearing aid appropriately and hearing aids for children often require a period of acclimatisation and acceptance which does not suit a fluctuating hearing loss. Sound-field amplification by allowing a consistent $10 \mathrm{~dB}$ extra signal provides one solution for the fluctuating hearing loss. Here the child, irrespective of whether they have the conductive hearing loss will always receive the extra $10 \mathrm{~dB}$ of amplification and the crucial improvement in signal-to-noise ratio.

The present study concludes that sound-field amplification improves the speech perception skills of children with Down syndrome and therefore, it can be argued that soundfield amplification will enhance listening and learning in the classroom. Research on the "real-life" effects of soundfield amplification in a classroom setting for children with Down syndrome has yet to be conducted. The results from this study, however, suggest the sound-field amplification in the classroom for children with Down syndrome is efficacious. Modern classrooms, often provide an inadequate listening environment particularly with regard to background noise. Various guidelines (ASHA, 1995; Crandell, Smaldino, \& Flexer, 1995) suggest that optimally the unoccupied classroom should have no more that 30 to $35 \mathrm{dBA}$ of background noise. Recent studies (Allcock, 1999; Arnhold \& Canning, 1999; Berg, 1993) found that the amount of background noise in unoccupied classrooms was between 52 and $85 \mathrm{dBA}$. Not surprisingly, these loud noise levels impact on the signal-to-noise level in the classroom. The more noise in the room, the more that noise can mask out the teacher's voice and thus make listening more difficult for the children and speaking more difficult for the teacher. For a child with normal hearing, the noise in the classroom must be $15 \mathrm{~dB}$ less than the teacher's voice (Finitzo, 1988) for the child to hear clearly. That provides a signal-to-noise level of $+15 \mathrm{~dB}$. In Blake and Busby's (1994) evaluation of the acoustical conditions in 106 classrooms the signal-tonoise level ranged from $0 \mathrm{~dB}$ to $+23 \mathrm{~dB}$. The authors concluded that only $4 \%$ of classrooms had acceptable noise levels for instruction.

The result of the present study that speech perception with sound-field amplification does not show a significant decline under conditions of increased noise is important. By raising the signal to the child's ears by only $10 \mathrm{~dB}$ compared with the noise level effectively improves the signalto-noise ratio within the classroom and leads to improved speech perception. Increased levels of background noise are inevitable within modern classrooms due to the increased emphasis on group work and activities. Sound-field amplification allows the child with Down syndrome to receive a good auditory signal in environments where without amplification the child would have great difficulty listening. At each background noise level the children performed better with the sound-field system. The addition of an extra $10 \mathrm{~dB}$ of signal to the teacher's voice even in conditions of a relatively good signal-to-noise ratio improved the child's speech perception. Previous research (Hodson \& Paden, 1993 ) showed that children with speech and language delay require additional amplification in the region of $10 \mathrm{~dB}$ to 
process speech. The results with the sound-field amplification system support this hypothesis.

The current study examined speech perception performance only. A child in a classroom must do more than just listen to speech. Instructions and information must be processed, comprehended and acted upon. Recent studies have found that sound-field amplification not just improves perception but also comprehension of speech (Arnhold \& Canning, 1999). Therefore, future research should ensure that children with Down syndrome also benefit in terms of comprehension from sound-field amplification.

The methods used in this study of comparing speech perception with and without sound-field are relatively easy and straight forward to carry out and need little specialised equipment. Therefore, the methodology could be replicated in other environments where there is a need to show improved performance with a sound-field system to justify a funding request.

Sound-field amplification improves the speech perception of children with Down syndrome and should therefore be a requirement of the educational setting for all children with Down syndrome. The results are consistent with previous research concluding that an optimum listening environment within the school benefits literacy, phonological awareness, speech and language skills, mathematical skills, vocabulary and word analysis, time on task, gifted as well as "at risk" children, normally hearing as well as hearingimpaired students and results in fewer teacher absences due to fatigue and laryngitis (Allcock, 1999; Arnhold \& Canning, 1999; Bess, Dodd-Murphy \& Parker 1998; Crandell et al., 1995; McSporran, 1997; Massie et al., 1999; Sapienza, et al., 1999). This investigation advocates that sound-field amplification should be used in the classrooms of children with Down syndrome to improve speech perception and intelligibility of the teacher.

\section{Acknowledgements}

The authors would like to thank the four families who gave of their time to support this research. The study by Marleen Westerveld into the hearing characteristics of a group of children with Down syndrome gave impetus to the development of the present study. Equipment for the study was provided by the Oticon Foundation in New Zealand and Phonic Ear Ltd. Funding for this research was provided by a summer studentship to the first author from the Canterbury Medical Research Foundation (CMRF).

\section{Correspondence}

Dr. Mark C. Flynn - Department of Speech and Language Therapy, University of Canterbury, Private Bag 4800, Christchurch, 8020, NEW ZEALAND • Email: m.flynn@spth.canterbury.ac.nz • Phone: +64-3-366-7001• Fax: +64-3-364-2760

\section{References}

Allcock, J. (1999). The effects of installing Phonic Ear FM sound-field amplification systems in junior classrooms. Unpublished manuscript.

American Speech-Language-Hearing Association (1995). Guidelines for acoustics in educational environments. ASHA, (Suppl. 14), 15-19.

Arnhold, P. \& Canning, D. (1999). Does classroom amplification aid comprehension? British Journal of Audiology, 33, 171-178.

Berg, F.S. (1987) Facilitating Classroom Listening: A Handbook for Teachers of Normal and Hard of Hearing Students. Boston: College Hill Press.

Berg, F.S. (1993). Acoustics and Sound Systems in Schools. San Diego: Singular Publishing Group Inc.

Bess, F.H., Dodd-Murphy, J. \& Parker, R.A. (1998). Children with minimal sensorineural hearing loss: Prevalence, educational performance and functional status. Ear and Hearing, 19, 339-354.

Blake, P., \& Busby, S. (1994). Noise levels in New Zealand junior classrooms: Their impact on hearing and teaching. The New Zealand Medical Journal, 107, 357-358.

Chapman, R.S., Schwartz, S.E. \& Bird, E. (1991). Language skills of children and adolescents with Down syndrome: I. Comprehension. Journal of Speech and Hearing Research, 34, 1106-1120.

Crandell, C., Smaldino, J. \& Flexer, C. (1995). Sound Field Amplification. Theory and Practical Applications. San Diego: Singular Publishing Company.

Davies, B. (1985). Hearing problems. In D. Lane \& B. Stratford (Eds.), Current Approaches to Down's Syndrome (pp. 85-102). London: Holt, Rinehart \& Wilson.

Finitzo, T. (1988). Classroom acoustics. In R. Roeser \& M. Downs (Eds.). Auditory Disorders in School Children (2nd edition, pp. 221-223). New York: Theime.

Flexer, C. (1997a). Individual and sound-field FM systems: Rationale, description, and used. The Volta Review, 99(3), 133-162.

Flexer, C. (1997b). Sound-field FM systems: Questions most often asked about classroom amplification. Hearsay, 11(2), 5-14.

Flynn, M.C. (2000). Square pegs in round holes: Do speechlanguage therapists have a role in providing services for the hearing impaired? New Zealand Journal of Speechlanguage Therapy, 54, 5-13.

Hodson, B.W. \& Paden, E.P. (1991) Targeting Intelligible Speech (2nd Edition). Austin: Pro-Ed.

Kendall, D. (1962) The Kendall Toy Test. In D.M. Dale (Ed.) Applied Audiology for Children. Springfield: Charles C. Thomas.

Massie, R., Theodoros, D., Byrne, B., McPherson, B. \& Smaldino, J. (1999). The effects of sound field classroom amplification on the communicative interactions of Aboriginal and Torres Strait Islander children. The Australian and New Zealand Journal of Audiology, 21(2), 93-109.

Maurizi, M., Ottaviani, F., Paludetti, G., \& Lungarotti, S. (1985). Audiological findings in Down's children. International Journal of Pediatric Otorhinolaryngology, 9, 227-232. 
McSporran, E. (1997). Towards better listening and learning in the classroom. Educational Review, 49, 102-111.

Miller, J.F., Leddy, M. \& Leavitt, L.A. (1999). Improving the Communication of People with Down Syndrome. Baltimore, MD: Paul H. Brookes.

Palmer, C.V. (1997). Hearing and listening skills in a typical classroom. Language, Speech and Hearing Services in Schools, 28, 213-218.

Roberts, J.E., Wallace, I.F. \& Henderson, F.W. (1997). Otitis Media in Young Children. Baltimore, MD: Paul H. Brookes.

Roizen, N.J., Wolters, C., Nicol, T. \& Blondis, T.A. (1993). Hearing loss in children with Down syndrome. Journal of Pediatrics, 123(1), S9-12.

Sapienza, C.M., Crandell, C.C. \& Curtis, B. (1999). Effects of sound-field frequency modulation on reducing teachers' sound pressure level in the classroom. Journal of Voice, 13(3), 375-381.

Schmidt, C., Andrews, M. \& McCutcheon, J. (1998). An acoustical and perceptual analysis of the vocal behaviour of classroom teachers. Journal of Voice, 12, 434-443.

Westerveld, M. \& Flynn, M. (2001). Management of hearing loss in children with Down syndrome. New Zealand Down Syndrome News, 11, 16-19. 